\title{
GUÍA DE REHABILITACIÓN VESTIBULAR
}

\section{Vestibular Rehabilitation Guide}

\author{
Ángel BATUECAS-CALETRÍO ${ }^{1}$; José Ignacio BENITO-OREJAS²; José Luis PARDAL-REFOYO1 \\ ${ }^{1}$ SACYL. Hospital Universitario de Salamanca. Servicio de Otorrinolaringología y CCF. Salamanca. España. \\ ${ }^{2}$ SACYL. Hospital Clínico Universitario de Valladolid. Servicio de Otorrinolaringología y CCF. Valladolid. España. \\ Correspondencia: jbenitoorejas@gmail.com
}

Fecha de publicación: 30 de diciembre de 2019

Fecha de publicación del fascículo: 1 de marzo de 2020

Conflicto de intereses: Los autores declaran no tener conflictos de intereses

Imágenes: Los autores declaran haber obtenido las imágenes con el permiso de los pacientes

Política de derechos y autoarchivo: se permite el autoarchivo de la versión post-print (SHERPA/RoMEO)

Licencia CC BY-NC-ND. Licencia Creative Commons Atribución-NoComercial-SinDerivar 4.0 Internacional

Universidad de Salamanca. Su comercialización está sujeta al permiso del editor

La Comisión de Otoneurología de Castilla y León, Cantabria y La Rioja, propuso en la IV Reunión Otoneurológica de la Sociedad Otorrinolaringológica de Castilla y León, Cantabria y La Rioja celebrada el 16 de marzo de 2019 en Logroño, elaborar una guía de rehabilitación vestibular (RV) con el objetivo de recopilar información reciente sobre los diferentes procedimientos para disponer de un conjunto de recomendaciones que pudieran ser útiles y aplicables en cualquier centro con los medios de que disponga.

La guía se estructura en diez temas, asumidos de forma voluntaria por compañeros de distintas provincias y que, tras varios meses de elaboración, se hacen ahora públicos. Creemos que se trata de un buen trabajo, eminentemente práctico, sobre los diferentes aspectos de este tratamiento, que resumimos a continuación, para facilitar al lector su contenido.

Ediciones Universidad de Salamanca / 요

Rev. ORL, 2020, 11, 1, 1-5
En el primer capítulo, los autores GonzálezSánchez y cols. [1] describen la sintomatología que acompaña a la hipofunción vestibular uni y bilateral, en sus distintas formas de presentación: aguda, recurrente o crónica. La anamnesis y los signos clínicos pueden conducirnos rápidamente a un diagnóstico de presunción, pero las pruebas complementarias vestibulares son las que corroboran y cuantifican el déficit del sistema. La correcta valoración contribuye al manejo específico de estas patologías, que tienen un impacto negativo en la vida del paciente, produciendo discapacidad, dependencia y un alto coste socioeconómico.

El mismo grupo de trabajo analiza a continuación la compensación vestibular [2], que definen, como un conjunto de procesos que se ponen en marcha cuando tiene lugar una lesión a nivel vestibular, sea cual sea el origen y la magnitud. Para 


\section{GUÍA DE REHABILITACIÓN VESTIBULAR \\ BATUECAS-CALETRÍO Á ET AL}

mejorar el estado de nuestros pacientes es importante conocer el fundamento de estos mecanismos de compensación. La recuperación del equilibrio se basa en la capacidad del sistema nervioso central para procesar la información que le llega desde un sistema sensorial deficitario.

El objetivo del trabajo elaborado por Fernández-Cascón y cols. [3], ha consistido en estandarizar la evaluación del paciente, para facilitar la comunicación entre el facultativo, que indica la RV y el responsable de realizarla. Por medio de la anamnesis, la aplicación de diferentes escalas y un conjunto de exploraciones consideradas como imprescindibles, se concluye que, la correcta realización de una evaluación individualizada es el pilar fundamental para orientar el tratamiento rehabilitador.

Tras valorar al paciente, debemos conocer si su situación entra dentro de las indicaciones consideradas eficaces para una RV. Las autoras Marta Alonso y Ana Sánchez [4] nos relatan la evolución terapéutica de los últimos años, que ha permitido ampliar el ámbito de actuación. En este capítulo se describen las indicaciones que actualmente se consideran de utilidad y aquellas que, aun no siendo validadas, son defendidas por muchos autores.

La primera terapia física de entrenamiento del equilibrio fue propuesta en los años 40 del siglo XX por Sir Terence Cawthorne y Harold Cooksey, incrementando su evidencia en los últimos veinte años y convirtiéndose actualmente en el tratamiento estándar de los pacientes con disfunción vestibular crónica. El equipo de fisioterapeutas y médicos rehabilitadores del Servicio de Rehabilitación del Hospital Clínico Universitario de Valladolid, nos exponen de forma práctica y con multitud de imágenes, la forma de llevar a cabo esta terapia [5]. Diferenciamos dos grandes grupos de ejercicios, según se dirijan al tratamiento de la hipofunción vestibular (objetivo de este tema), o a la reposición de partículas en el caso del vértigo posicional paroxístico benigno, que ya ha sido revisado anteriormente [6].

Ediciones Universidad de Salamanca / @D@®
La inestabilidad en el anciano es de origen multifactorial y no obedece solamente a razones fisiológicas. Virginia Franco y Paz Pérez, explican la necesidad de identificar los factores precipitantes para aplicar un tratamiento y si fuera posible, realizar un abordaje multidisciplinar que minimice la morbimortalidad asociada a este proceso [7]. La RV puede mejorar el equilibrio de las personas mayores con inestabilidad, conduciendo a una reducción significativa de las caídas y a una mejora de su calidad de vida.

En la disfunción vestibular crónica es frecuente que se incremente el mareo o el desequilibrio con el propio movimiento o con el de un ambiente visual sobrecargado, lo que se denomina dependencia visual. En otras ocasiones, la dependencia es somatosensorial y el paciente pierde con facilidad el equilibrio al alterarse la superficie de soporte. Bauer y cols., describen en este tema las características de la dependencia [8]. El tratamiento se basa en la terapia física, la realidad virtual y la estimulación optocinética progresiva, con el objetivo de desensibilizar al individuo y mejorar su sintomatología.

Cordero-Civantos y cols. [9], presentan un artículo en el que exponen cómo llevar a cabo la RV con posturografía dinámica computarizada. Su aplicación nos permite realizar una valoración global del equilibrio, analizando cada sistema sensorial y posibilita el diseño de una estrategia de rehabilitación adaptada a cada paciente. No obstante, se considera importante complementarla con otras técnicas y ejercicios, seleccionados de forma individualizada.

Las nuevas tecnologías ofrecen diferentes fórmulas para estudiar y modificar la relación del sujeto con el medio. Rafael Álvarez analiza las ventajas e inconvenientes de la realidad virtual y de otros dispositivos, frente a la terapia física convencional [10]. Se trata de una fisioterapia más lúdica, que facilita la adherencia al tratamiento e incorpora su propio sistema de evaluación, pero se necesitan más ensayos clínicos para valorar su eficacia y una mayor colaboración entre ingenieros, clínicos e 


\section{GUÍA DE REHABILITACIÓN VESTIBULAR \\ BATUECAS-CALETRÍO Á ET AL}

investigadores para optimizar estos nuevos instrumentos.

No hay un programa único que pueda ser eficaz a todo el que sufre de un trastorno vestibular. Benito y cols. [11], señalan la falta de consenso respecto a la frecuencia, duración óptima y número total de visitas necesarias para obtener los mejores resultados, que dependerá de la respuesta del paciente. El conocimiento actual corrobora la utilidad de la rehabilitación vestibular en disfunciones vestibulares periféricas y centrales, mejorándose la sintomatología vertiginosa, el riesgo de caídas, el equilibrio y el estado emocional del paciente, siendo además un tratamiento coste-efectivo.

Nuestro agradecimiento a la Dra. Cristina Cordero-Civantos por presentar el proyecto de esta guía en la IV Reunión de Otoneurología 2019 celebrada en Logroño y a todos los colaboradores, cuyo trabajo permitirá la difusión de este conocimiento, facilitando su aplicación en los pacientes con insuficiencia vestibular y contribuyendo a la mejora de su sintomatología y calidad de vida.

\section{REFERENCIAS}

1. González-Sánchez M, Coscarón-Blanco E, MartínSánchez V, Yáñez-González R, Martín-Bailón M, Sánchez-Blanco C, Sánchez-Gómez H. Síntomas y signos de la hipofunción vestibular unilateral y bilateral. Rev ORL [Internet]. 2 Dic 2019 [citado 30 Dic 2019]; 9p. Disponible en: http://revistas. usal.es/index.php/2444-7986/article/view/21625. DOI: http://dx.doi.org/10.14201/orl.21625.

2. Martín-Bailón M, Yáñez-González R, SánchezGómez H, Sánchez-Blanco C, González-Sánchez M, Martín-Sánchez V, Coscarón-Blanco E. Compensación vestibular. Rev ORL [Internet]. 15 Oct 2019 [citado 30 Dic 2019]; 10p. Disponible en: http://revistas.usal.es/index.php/2444-7986/article/ view/21381. DOI: http://dx.doi.org/10.14201/ orl.21381.

3. Fernandez-Cascon S, Rettig-Infante I, MoralesMedina G, Buendia-Pajares C. Evaluación del paciente previa a la rehabilitación vestibular. Rev ORL [Internet]. 30 Ago 2019 [citado 30 Dic 2019]; 13p. Disponible en: http://revistas.usal.es/index. php/2444-7986/article/view/21292. DOI: http:// dx.doi.org/10.14201/orl.21292.

4. Alonso-Mesonero M, Sánchez-Martínez A. Indicaciones de la rehabilitación vestibular. Rev ORL [Internet]. 18 Dic 2019 [citado 30 Dic 2019]; 7P. Disponible en: http://revistas.usal.es/index. php/2444-7986/article/view/21814. DOI: http:// dx.doi.org/10.14201/orl.21814.

5. Benito-Orejas J, Aylagas-Andrés M, MartínMoratinos C, Gallardo-Chaparro I, Pérez-Hickman L, Aladro-Abad V, et al. Terapia física en la hipofunción vestibular unilateral y bilateral. Rev ORL [Internet]. 22 Jul 2019 [citado 30 Dic 2019]; 15p. Disponible en: http://revistas.usal.es/index. php/2444-7986/article/view/21022. DOI: http:// dx.doi.org/10.14201/orl.21022.

6. Benito-Orejas J, Poncela-Blanco M, Diez-González L, Álvarez-Otero R, Aguilera-Aguilera G, Intraprendente-Martini J, et al. Guía práctica del vértigo posicional paroxístico. Rev ORL [Internet]. 1 Sep 2017 [citado 30 Dic 2019]; 8(3): 157-196. Disponible en: http://revistas.usal.es/index.php/24447986/article/view/15655. DOI: http://dx.doi. org/10.14201/orl.15655.

7. Franco-Gutiérrez V, Perez-Vázquez P. Rehabilitación vestibular en personas mayores con disfunción vestibular. Rev ORL [Internet]. 14 Jul 2019 [citado 30 Dic 2019]; 11p. Disponible en: http://revistas. usal.es/index.php/2444-7986/article/view/20953. DOI: http://dx.doi.org/10.14201/orl.20953.

8. Bauer M, Benito-Orejas J, Ramírez-Salas J. Rehabilitación vestibular en la dependencia visual y somatosensorial. Rev ORL [Internet]. 28 Sep 2019 [citado 30 Dic 2019]; 9p. Disponible en: http:// revistas.usal.es/index.php/2444-7986/article/ view/21241. DOI: http://dx.doi.org/10.14201/ orl.21241.

9. Cordero-Civantos C, Calle-Cabanillas M, ÁlvarezGómez L. Rehabilitación vestibular con posturografía dinámica. Rev ORL [Internet]. $15 \mathrm{Oct}$ 2019 [citado 30 Dic 2019]; 6p. Disponible en: http://revistas.usal.es/index.php/2444-7986/article/ view/21512. DOI: http://dx.doi.org/10.14201/ orl.21512. 


\section{GUÍA DE REHABILITACIÓN VESTIBULAR \\ BATUECAS-CALETRÍO Á ET AL}

10. Álvarez-Otero R. Revisión sobre la aplicación de la realidad virtual en la rehabilitación vestibular. Rev ORL [Internet]. 10 Ago 2019 [citado 30 Dic 2019]; 10p. Disponible en: http://revistas.usal.es/ index.php/2444-7986/article/view/21215. DOI: http://dx.doi.org/10.14201/orl.21215.

11. Benito-Orejas J, Alonso-Vielba J, Valda-Rodrigo J, Cifuentes-Navas V. Resultados y seguimiento de la rehabilitación vestibular. Rev ORL [Internet]. 11 Sep 2019 [citado 30 Dic 2019]; 8p. Disponible en: http://revistas.usal.es/index.php/24447986/article/view/21243. DOI: http://dx.doi. org/10.14201/orl.21243.

\section{OTRAS REFERENCIAS}

III Jornada otoneurológica de la Sociedad Otorrinolaringológica de Castilla y León, Cantabria y La Rioja. Zamora, 17 de marzo de 2018.

En Rev ORL. 2018;9(2):95-167. http://revistas.usal.es/ index.php/2444-7986/issue/view/939/showToc. DOI: http://dx.doi.org/10.14201/orl.201892.

En Rev ORL. 2018;9(3):169-245. http://revistas. usal.es/index.php/2444-7986/issue/view/990/ showToc. DOI: http://dx.doi.org/10.14201/ orl.201893.

12. Martín-Sanz E. La exploración, nuestra mejor aliada. Rev ORL [Internet]. 30 Abr 2018 [citado 30 Dic 2019]; 9(2): 95-96. Disponible en: http:// revistas.usal.es/index.php/2444-7986/article/ view/18270. DOI: http://dx.doi.org/10.14201/ orl.18270.

13. Valda-Rodrigo J, Benito-Orejas J, Alonso-VielbaVarea J. Revisión sobre el vértigo cervical. Rev ORL [Internet]. 18 Nov 2017 [citado 30 Dic 2019]; 9(2): 97-104. Disponible en: http://revistas. usal.es/index.php/2444-7986/article/view/17191. DOI: http://dx.doi.org/10.14201/orl.17191.

14. Benito-Orejas J, Valda-Rodrigo J, Alonso-VielbaVarea J. Revisión sobre el nistagmo posicional. Rev ORL [Internet]. 24 Nov 2017 [citado 30 Dic 2019]; 9(2): 105-110. Disponible en: http:// revistas.usal.es/index.php/2444-7986/article/ view/17190. DOI: http://dx.doi.org/10.14201/ orl.17190.

Ediciones Universidad de Salamanca / @@@
15. Fernández-Cascón S, Fernández-Moráis R, Álvarez-Otero R. Revisión sobre la importancia clínica del nistagmo espontáneo y de la prueba de agitación cefálica. Rev ORL [Internet]. $30 \mathrm{Nov}$ 2017 [citado 30 Dic 2019]; 9(2): 111-119. Disponible en: http://revistas.usal.es/index.php/24447986/article/view/17173. DOI: http://dx.doi. org/10.14201/orl.17173.

16. Santos-Gorjón P. Revisión sobre la agudeza visual dinámica. Rev ORL [Internet]. 8 Dic 2017 [citado 30 Dic 2019]; 9(2): 121-126. Disponible en: http:// revistas.usal.es/index.php/2444-7986/article/ view/17139. DOI: http://dx.doi.org/10.14201/ orl.17139.

17. Mena-Domínguez E. Revisión sobre la desviación oblicua. Rev ORL [Internet]. 8 Dic 2017 [citado 30 Dic 2019]; 9(2): 127-131. Disponible en: http:// revistas.usal.es/index.php/2444-7986/article/ view/17348. DOI: http://dx.doi.org/10.14201/ orl.17348.

18. Mena-Domínguez E. Revisión sobre la prueba de hiperventilación y la de Valsalva. Rev ORL [Internet]. 18 Dic 2017 [citado 30 Dic 2019]; 9(2): 133-137. Disponible en: http://revistas.usal.es/ index.php/2444-7986/article/view/17385. DOI: http://dx.doi.org/10.14201/orl.17385.

19. Sánchez-Gómez H, Marco-Carmona M, Intraprendente-Martini J. Exploración vestibuloespinal. Rev ORL [Internet]. 5 Ene 2018 [citado 30 Dic 2019]; 9(2): 139-143. Disponible en: http:// revistas.usal.es/index.php/2444-7986/article/ view/17424. DOI: http://dx.doi.org/10.14201/ orl.17424.

20. Pardal-Refoyo J, Batuecas-Caletrío Á. Revisión sobre los instrumentos de evaluación de la discapacidad en patología vestibular. Rev ORL [Internet]. 30 Ene 2018 [citado 30 Dic 2019]; 9(2): 145-164. Disponible en: http://revistas.usal.es/ index.php/2444-7986/article/view/17700. DOI: http://dx.doi.org/10.14201/orl.17700.

21. Franco-Gutiérrez V, Pérez-Vázquez P. Exploración oculomotora. Rev ORL [Internet]. 18 Ene 2018 [citado 30 Dic 2019]; 9(3): 169-192. Disponible en: http://revistas.usal.es/index.php/24447986/article/view/17697. DOI: http://dx.doi. org/10.14201/orl.17697. 


\section{GUÍA DE REHABILITACIÓN VESTIBULAR \\ BATUECAS-CALETRÍO Á ET AL}

22. Pérez-Vázquez P, Franco-Gutiérrez V. La prueba calórica. Rev ORL [Internet]. 18 Ene 2018 [citado 30 Dic 2019]; 9(3): 193-213. Disponible en: http:// revistas.usal.es/index.php/2444-7986/article/ view/17699. DOI: http://dx.doi.org/10.14201/ orl.17699.

23. González-Aguado R. Prueba rotatoria. Técnica e interpretación. Rev ORL [Internet]. 16 Feb 2018 [citado 30 Dic 2019]; 9(3): 215-219. Disponible en: http://revistas.usal.es/index.php/24447986/article/view/17717. DOI: http://dx.doi. org/10.14201/orl.17717.

24. Sánchez-Blanco C, Yáñez-González R, BatuecasCaletrío Á. Nistagmo inducido por vibración en Otorrinolaringología. Rev ORL [Internet]. 20 Dic 2017 [citado 30 Dic 2019]; 9(3): 221-226. Disponible en: http://revistas.usal.es/index.php/2444- 7986/article/view/17393. DOI: http://dx.doi. org/10.14201/orl.17393.

25. Cordero-Civantos C, Calle-Cabanillas M. Primeros pasos en la posturografía dinámica computarizada. Rev ORL [Internet]. 13 Dic 2017 [citado 30 Dic 2019]; 9(3): 227-237. Disponible en: http:// revistas.usal.es/index.php/2444-7986/article/ view/17370. DOI: http://dx.doi.org/10.14201/ orl.17370.

26. Pérez-González R, Gancedo-Fernández S. Percepción de la vertical visual subjetiva. Medición y utilidad diagnóstica. Rev ORL [Internet]. 22 Ene 2018 [citado 30 Dic 2019]; 9(3): 239-245. Disponible en: http://revistas.usal.es/index.php/24447986/article/view/17698. DOI: http://dx.doi. org/10.14201/orl.17698. 
